\title{
THE EFFECTS OF RECYCLING PALM PRESSED- FIBRE OIL ON CRUDE PALM OIL QUALITY
}

\author{
HASLIYANTI, A*; RUSNANI, A M*; WAN HASAMUDIN, W $\mathrm{H}^{*}$; NG, M $\mathrm{H}^{*}$; NOR FAIZAH, J \\ and ROHAYA, M H*
}

\begin{abstract}
Palm pressed-fibre oil (PPFO) is known as a phytonutrients rich oil. PPFO was practically recycled back to the crude palm oil (CPO) processing line to increase oil extraction rates. This study evaluated the effect of blending CPO with PPFO at different PPFO dosage from $5 \%-25 \%(w / w)$ on blended oil quality. Free fatty acid (FFA) of blended oils increased from 3.42\%-3.91\%, while deterioration of bleachability index (DOBI) and iodine value (IV) decreased from 2.76 to 2.33 and $51.96 \pm 0.37$ to $50.21 \pm 0.03$, respectively. Minor components amount in blended oils were found to increase with carotenoids (539-654 ppm), squalene (475$1201 \mathrm{ppm})$, sterols (433-808 ppm), phospholipids (34.67-63.84 ppm) and vitamin E (1185-1626 ppm). The oxidative stability of blended oils was improved (14.31-16.76 hr) but chlorine, iron and copper content were found to increase from 3.85-7.49 ppm, 13.58-17.63 ppm and 0.19-0.38 ppm, respectively. Although blending PPFO would deteriorate some quality properties of CPO, nonetheless, PPFO is rich with phytonutrients, therefore signifying its potential applications in pharmaceuticals and food industry.
\end{abstract}

Keywords: blending PPFO, chloride, crude palm oil, heavy metals, oil quality, palm pressed-fibre oil.

Received: 23 December 2020; Accepted: 17 February 2021; Published online: 26 April 2021.

\section{INTRODUCTION}

The rapid increase in palm oil production over the last few decades has made it as one of the most important oils in the world. Malaysia contributes to almost $30 \%$ of global palm oil production and $36 \%$ of the world exporters in 2019 (Workman, 2020). Parveez et al. (2020) reported that oil palm planted areas in Malaysia increased to 5.90 million hectares and fresh fruit bunches (FFB) yield of $17.19 \mathrm{t} \mathrm{ha}^{-1}$ in 2019. This would contribute to a generation of massive amount of solid wastes, in the form of lignocellulosic residues from replanting activities and oil mill processing, stemming from oil palm trunk (OPT), oil palm frond (OPF), empty fruit bunches (EFB), palm pressed mesocarp fibre (PPMF), palm kernel cake (PKC), palm kernel shell (PKS) and decanter cake. Solid wastes produced

\footnotetext{
Malaysian Palm Oil Board,

6 Persiaran Institusi, Bandar Baru Bangi,

43000 Kajang, Selangor, Malaysia.

E-mail: hasliyanti@mpob.gov.my
}

were 20\%-28\% EFB, 11\%-12\% PPMF and 5\%-8\% PKS (Yusoff, 2006; Sarmidi et al., 2009; Awalludin et al., 2015; Onoja et al., 2019).

PPMF is a by-product produced after crude palm oil $(\mathrm{CPO})$ is extracted from the digested oil palm fruits mash, using a screw press. PPMF contains a substantial amount of residual oil (5\%$8 \%$ ) that is usually burnt along with the PPMF in the boiler, in order to supply energy to the mill. Several techniques to recover the residual oils from PPMF have been reported, such as, solvent extraction, enzymatic treatment, supercritical carbon dioxide (SC-CO2) and remnant oil recovery (ROR) system (Lau et al., 2006; Vijaya et al., 2013; Noorshamsiana et al., 2017; Nur Sulihatimarsyila et al., 2019). The residual oil extracted from this technique is known as palm pressed-fibre oil (PPFO). The commercial extraction technique of PPFO from PPMF is solvent extraction using hexane (Nur Sulihatimarsyila et al., 2019). According to a survey done by Malaysian Palm Oil Board (MPOB), the system has been commercially installed in 12 palm oil mills in Malaysia (Ummi Kalsum and Rohaya, 
2019). Non-polar solvent, namely hexane is utilised for extraction. This technique has been used in various vegetable oil extractions, such as rapeseed and soyabean (Kumar et al., 2017). Many studies reported that PPFO is rich with carotenoids, vitamin $\mathrm{E}$ (tocopherol and tocotrienols) (Goh et al., 1985; Choo et al., 1996; Ng and Choo, 2011; Rusnani et al., 2012; Lau et al., 2017; Noorshamsiana et al., 2017; Nur Sulihatimarsyila et al., 2019), squalene and sterols (Goh et al., 1985; Choo et al., 1996; Lau et al., 2007; Ng and Choo, 2011; Phoon et al., 2018). Since PPFO is rich in natural phytonutrients, almost all previous studies had suggested that PPFO has a wide range of applications in pharmaceuticals, supplementation and cosmetics (Lau et al., 2017; Nur Sulihatimarsyila et al., 2019). PPFO was also found to contain high amounts of water-soluble compounds, such as phospholipids (217-1063 ppm) and phenolics with outstanding antioxidant activities (Ummi Kalsum and Rohaya, 2019; Lau et al., 2007; Valeria et al., 2017). Apart from the normal fatty acid composition (FAC) content, PPFO has high diaclyglycerol (DAG) and triacylglycerol (TAG) $(67.04 \% \pm 0.05)$ with acceptable amount of monoaclyglycerol (MAG)/ free fatty acid (FFA) $(13.02 \% \pm 0.02)$ compositions. Nonetheless, PPFO also contains substantial amount of lauric acid $(5.89 \%-9.09 \%)$ due to broken kernels in the mesocarp fibre, thus, making it suitable for the food applications and industry (Neoh et al., 2011; Lau et al., 2006).

However, studies also showed that PPFO is low in quality compared to CPO. Ummi and Rohaya (2019) reported on the deterioration of bleachability index (DOBI) of the PPFO, which ranges from 1.15-2.17 while the FFA ranges from $5.09 \%-10.6 \%$ as shown in Table 1. Also, PPFO has a high content of chlorine (207.62-379.58 ppm) which will lead to formation of carcinogenic compounds such as 3-monochloropropane-1,2-diols (3-MCPD) esters (Table 1) (Ummi Kalsum and Rohaya, 2019; Ramli et al., 2015). Therefore, PPFO can only be sold at a lower price as compared to CPO because PPFO has not been classified into any oil classification set by MPOB. Since it is chemically extracted, it is therefore forbidden to blend PPFO into the CPO processing line (Ummi Kalsum and Rohaya, 2019). Since PPFO is not under any of the palm oil categories, it is automatically classified as sludge oil, which is the lowest quality of palm oil grade, in terms of price. As a result, palm oil millers tend to blend PPFO into CPO to increase its oil extraction rate. Apparently, the practice of blending PPFO into $\mathrm{CPO}$ has been increasing in recent years, as indicated by the increment of phosphorous content and FFA in CPO (Ummi Kalsum and Rohaya, 2019). According to the Code of Good Milling Practice of Palm Oil Mills (GMP), residual oils cannot be recycled or blended with $\mathrm{CPO}$, mainly due to quality deterioration. Nevertheless, the blending effect of PPFO on CPO quality is not extensively studied and reported. Therefore, this study is aimed to examine the quality of PPFO from commercial solvent extraction plant as well as to evaluate the characteristics of blended oil when different dosage of PPFO is used to blend with CPO.

\section{MATERIALS AND METHODS}

\section{Materials}

$\mathrm{CPO}$ and solvent extracted PPFO were collected from eight palm oil mills and eight solvent extraction plants located in central, southern and northern region of Peninsular Malaysia. The samples were freshly collected and kept in the chiller at $4^{\circ} \mathrm{C}$ prior to the blending study. The PPFO samples collected from eight solvent extractions were used to determine the initial quality properties of PPFO. While, PPFO and CPO samples collected from Sitiawan, Perak and Labu Palm Oil Mill, Negeri Sembilan, Malaysia respectively, were used to evaluate the effect of blending CPO with PPFO at different dosages from $0 \%-25 \%(\mathrm{w} / \mathrm{w})$ at $60^{\circ} \mathrm{C}$ and $300 \mathrm{rpm}$ for 20 min on residual hexane concentration, FFA, DOBI, oxidative stability, iodine value (IV), trace elements, chloride content, phytonutrients content, FAC and acylglycerols compositions. All solvents, chemicals and reference standards (analytical grades) used in this study were purchased from Merck, JT Baker and Sigma, Germany.

\section{Analysis of Quality Properties}

The PPFO, CPO and blended oils samples were analysed according to MPOB Test Method (MPOB, 2005) to quantify the FFA, DOBI, carotene content, IV and phosphorus content.

\section{Hexane Residual Analysis using Headspace Chromatography}

Headspace analyses was performed by using GC-FID (6890N; Agilent Technologies, Santa Clara, CA, USA) and the headspace-sampler (HS-20; Shimadzu), which was used as preprocessing device (Kumar and Gow, 1994; Jeong et al., 2017). Gas flow

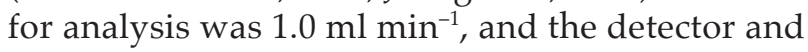
injection temperatures were regulated at $100^{\circ} \mathrm{C}$ and $50^{\circ} \mathrm{C}$, respectively. The column used was $30 \mathrm{~m} \times 0.3$ $\mathrm{mm} \times 0.2 \mu \mathrm{m}$ coated with methylpolysiloxane. The analysis was implemented in a 100:1 split mode by applying helium as carrier gas. Residual solvent content was expressed in $\mathrm{mg} \mathrm{kg}^{-1}$ (ppm) of the sample. 
Heavy Metals Concentration Analysis using Flame Atomic Adsorption Spectroscopy (FAAS)

The metals content such as iron $(\mathrm{Fe})$ and copper (Cu) was determined using Atomic Adsorption Spectrophotometer (AA-7000F, Shimadzu, Japan). Samples of $2 \mathrm{~g}$ each were weighed in $250 \mathrm{ml}$ round bottom flask, later added with $5 \mathrm{ml}$ of nitric acid $\left(\mathrm{HNO}_{3}\right), 5 \mathrm{ml}$ sulphuric acid $\left(\mathrm{H}_{2} \mathrm{SO}_{4}\right)$ and $2 \mathrm{ml}$ hydrogen peroxide $\left(\mathrm{H}_{2} \mathrm{O}_{2}\right)$. The mixture was then heated using water bath at $100^{\circ} \mathrm{C}$ until a clear solution was obtained. The solution was then filtered and made up to $50 \mathrm{ml}$ using ultrapure water and transferred to a plastic bottle for metal analysis by atomic adsorption spectroscopy (AAS).

\section{Total Chlorine Content Analysis}

The amount of chloride in CPO, PPFO and blended oils was measured using a Total Chlorine Analyser (TCA) NSX-2100H (Mitsubishi Chemical Analytech, Kanagawa, Japan). Samples were prepared according to American Society for Testing and Materials (ASTM) D4929-04 method (ASTM, 2004). The operation principle of TCA was combustion and microoulometry. In the presence of oxygen and argon as a carrier gas, $0.065 \mathrm{~g}$ of oil aliquot was combusted in the TCA at temperatures between $800^{\circ} \mathrm{C}-1000^{\circ} \mathrm{C}$. The hydrogen chloride released as a result of the combustion was then titrated with silver ion emitted from the titration cell. Chlorine content is quantified based on the intensity of electrical current released in the microcoulometer throughout the titration stage (Azmil et al., 2019).

\section{Oxidative Stability Analysis}

The oil stability was determined using Rancimat Analyser (743 Metrohm, Switzerland). Oil samples of $3.0 \pm 0.1 \mathrm{~g}$ each were weighed in a glass vessel. The temperature of heating block was set to $120^{\circ} \mathrm{C}$, while the gas flow was set to 20 litre $\mathrm{hr}^{-1}$ (Farhoosh, 2007).

\section{Fatty Acid Compositions (FAC) Analysis}

FAC were determined using gas chromatography flame ionisation (GC-FID) (Agilent Technologies). The samples were analysed according to American Oil Chemists' Society (AOCS) Official Method Ce 2-66 (AOCS 1997).

Triacylglycerols (TAG) Analysis by Ultra-highPerformance Liquid Chromatography (U-HPLC)

TAG analysis was performed by U-HPLC (ACQUITY UPLC H-Class System, Waters Corp., Milford, Massachusetts, USA) according to the AOCS Official Methods Ce 5c-89 and Ce 5c-93 (AOCS 1997). Individual samples were solubilised in acetone to form a $5 \% \mathrm{w} / \mathrm{v}$ solution. The solution was then filtered through a $0.2 \mu \mathrm{m}$ syringe filter. Exactly $1 \mu \mathrm{l}$ of the solution was then injected through an ACQUITY UPLC $®$ BEH C18 column (Waters Corp., Milford, Massachusetts, USA) with particle size of $1.7 \mu \mathrm{m}$, i.d. $2.1 \mathrm{~mm} \times 150 \mathrm{~mm}$ length, and maintained at $30^{\circ} \mathrm{C}$. The flowrate was fixed at $0.25 \mathrm{ml} \mathrm{min}^{-1}$. TAG were detected using refractive index detector set at $35^{\circ} \mathrm{C}$ with full scale setup at $100 \mu \mathrm{RIU}$ for 20-30 min of total run times.

\begin{tabular}{|c|c|c|c|c|c|}
\hline & $\begin{array}{c}\mathrm{CPO} \\
\text { (this study) }\end{array}$ & $\begin{array}{c}\text { PPFO } \\
\text { commercial I } \\
\text { (this study) }\end{array}$ & $\begin{array}{c}\text { PPFO } \\
\text { commercial II } \\
\text { (Ummi Kalsum and } \\
\text { Rohaya, 2019) }\end{array}$ & $\begin{array}{c}\text { PPFO } \\
\text { commercial III } \\
\text { (Nur Sulihatimarsyila } \\
\text { et al., 2019) }\end{array}$ & $\begin{array}{c}\text { MS 814:2007 } \\
\text { specification } \\
\text { (Farah Khuwailah } \\
\text { et al., 2019) }\end{array}$ \\
\hline FFA $(\%)$ & $3.1-4.5$ & $5.38-8.26$ & $5.09-10.6$ & $5.30 \pm 0.19$ & $<5 \%$ \\
\hline DOBI val & $2.43-2.83$ & $1.62-2.02$ & $1.15-2.17$ & $2.02 \pm 0.18$ & $>2.3$ \\
\hline Oxidative stability (hr) & $14-17$ & $18-25$ & - & - & - \\
\hline Iodine value (ppm) & $49.11-51.22$ & $51.96-53.22$ & - & - & $52 \pm 0.66$ \\
\hline Phosphorus content (ppm) & $16-27$ & $214-247$ & $217-1063$ & $633 \pm 83$ & $<10$ \\
\hline Chloride content (ppm) & $1.95-10.89$ & $23.41-127.23$ & $207.62-379.58$ & - & - \\
\hline Carotene content (ppm) & $537-572$ & $1258-1750$ & $1025-1913$ & $1467 \pm 35$ & $500-600$ \\
\hline Vitamin E (ppm) & $771-1108$ & $1686-2600$ & $1574-2999$ & $1527 \pm 73$ & - \\
\hline Hexane concentrations (ppm) & $\mathrm{N} / \mathrm{A}$ & $111-4046$ & - & - & - \\
\hline
\end{tabular}

Note: The solvent extracted PPFO was collected from: (I) eight, (II) nine, (III) one, solvent extraction plants in Peninsular Malaysia. Results are mean values and \pm standard deviation $(n=3)$ of oil samples.

FFA - free fatty acid; DOBI - deterioration of bleachability index; N / A - not applicable. 


\section{Vitamin E}

The vitamin E (tocopherols and tocotrienols) content was determined using HPLC and fluorescence detector (Agilent Technologies), with C18 column (150 mm x $4.6 \mathrm{~mm}$ i.d.). Mobile phase was acetonitrile/methanol (50:50 v/v) with $1.0 \mathrm{ml}$ $\min ^{-1}$ flow.

\section{Squalene and Sterols}

CPO, PPFO and blended samples were pretreated using saponification method prior to analyses of sterols and squalene following the MPOB Test Method (MPOB, 2005). Samples weighing $5.0 \mathrm{~g}$ each were mixed with $2.5 \mathrm{~g} 10 \%$ $(\mathrm{w} / \mathrm{v})$ potassium hydroxide $(\mathrm{KOH})$ in an ethanolic solution. The mixture was refluxed for $1 \mathrm{hr}$ at temperatures between $70^{\circ} \mathrm{C}-80^{\circ} \mathrm{C}$. Hexane was used to extract the unsaponifiable matters from the saponified mixture. Hexane was then removed from the mixture using rotary evaporator and the extracts were then washed using distilled water until a neutral $\mathrm{pH}$ was obtained. The remaining moisture was removed using sodium sulphate $\left(\mathrm{Na}_{2} \mathrm{SO}_{4}\right)$. The samples were then dissolved in $100 \% n$-hexane to an appropriate concentration. The diluted samples were analysed using gas chromatography (GC) Autosystem XL, Perkin Elmer with FID. The samples were separated in the capillary column purchased from Supelco SAC ${ }^{\mathrm{TM}}$-5 (Sigma) (30 mm x $0.25 \mathrm{~mm}$ i.d.) bonded with a $0.25 \mu \mathrm{m}$ film of $5 \%$ phenyls $/ 95 \%$ dimethylpolysiloxane in the presence of helium gas as mobile phase (Nor Faizah et al., 2020).

\section{RESULTS AND DISCUSSIONS}

\section{Effect on Residual Hexane Concentration}

Figure 1 shows the typical flow process of the solvent extraction system that has been commercially used in Malaysia. A non-polar solvent, hexane, is utilised for extraction. This solvent has been used in various vegetable oil extractions, such as rapeseed and soyabean (Kumar et al., 2017). Hexane is one of the most widely used solvents in edible oil extractions due to its excellent performance in oil recovery, high solubilising ability and evaporation at narrow boiling temperature $\left(63^{\circ} \mathrm{C}-69^{\circ} \mathrm{C}\right)$ (Kumar et al., 2017). Solvent extraction for PPFO production uses high temperatures between $80^{\circ} \mathrm{C}-140^{\circ} \mathrm{C}$. The solvent, evaporated through desolventisation of PPF in the desolventiser-toaster (Figure 1) and from miscella in the distillation column was carried over into atmospheric condenser to be converted into liquid and later deposited back into the solvent tank (Serrato, 1981). However, there is still excess solvent that would probably be trapped in the miscella which contains oil, gums, waxes and water. Hexane would likely be eliminated further during the refining stage since it is a compulsory process before the oil can be used as a food product. The final product could still contain traces amount of hexane. Several studies revealed that hexane is the most toxic of the alkanes group. If ingested, it causes nausea, vertigo, bronchial and intestinal irritation and affects the central nervous system. A study showed that there was no effect on human if exposed at concentration of up to 2000 ppm. However, it would cause dizziness, slight nausea, headache, and eye and throat irritations if exposed at 5000 ppm concentration (Clough, 2014). Therefore, it is desirable for the trace hexane in edible oil to be as low as possible.

Maximum residual level (MRL) of hexane has been established by various organisations and countries. European Union (EU) regulates the limit of hexane residues at 1 ppm (maximum) (Yousefi and Hosseini, 2017), while in Korea, the maximum level is 5 ppm (Oh et al., 2005). Static headspace analyses using GC-FID and gas chromatography mass spectrometric detector (GC-MSD) were developed to detect residual hexane in food and edible oil products (Oh et al., 2005; Jeong et al., 2017; Yousefi and Hosseini, 2017; Othman et al., 2019). Table 1 shows the residual hexane concentrations in $\mathrm{PPFO}$ collected from eight solvent extraction plants in Malaysia. The hexane's concentration in PPFO ranged from 111-4046 ppm. Results showed that the hexane level in blended oils increased with the increment in PPFO dosage (from $5 \%-25 \% \mathrm{w} / \mathrm{w}$ of $\mathrm{CPO})$, ranging from $3 \pm 0.04 \mathrm{ppm}$ to $18 \pm 0.2 \mathrm{ppm}$, respectively (Figure 2). These results indicated that hexane level in blended oils depended on the initial concentration of residual hexane in PPFO.

\section{Effect on Free Fatty Acid (FFA)}

The FFA content in palm oil indicates the deterioration level of oil, which then determines the value of the oil (Saad et al., 2007; Japir et al., 2017). Table 1 depicts the respective quality of $\mathrm{CPO}$ and PPFO from this study compared to other researchers' findings. Results showed that PPFO has higher FFA values compared to CPO. The FFA values of PPFO and CPO were 5.38\%-8.26\% and $3.1 \%-4.5 \%$, respectively. The maximum level of FFA value in CPO is below 5\%, as specified by Palm Oil Refiners Association Malaysia (PORAM) in Malaysian Standard MS814:2007 (Farah Khuwailah et al., 2019). Ummi Kalsum and Rohaya (2019) reported that FFA values of PPFO produced from nine solvent extraction plants in their survey were in the range of $5.1 \%-10.6 \%$ (Table 1 ), higher than those of CPO. PPFO's inferior quality could be contributed by longer storage and exposure of PPMF to atmospheric conditions prior to extraction (Rusnani et al., 2012; Neoh et 


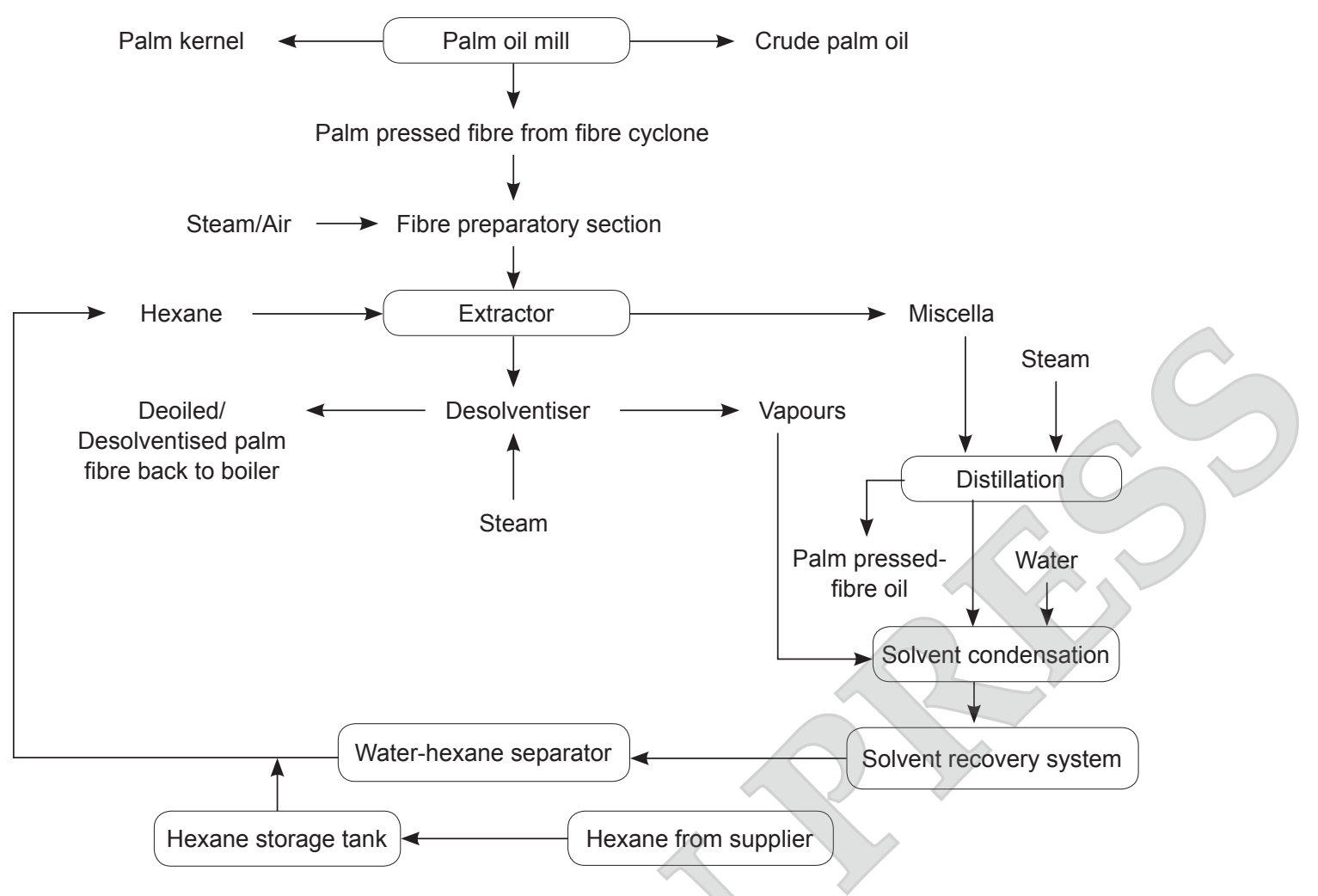

Figure 1. Process flow of solvent extraction plant.

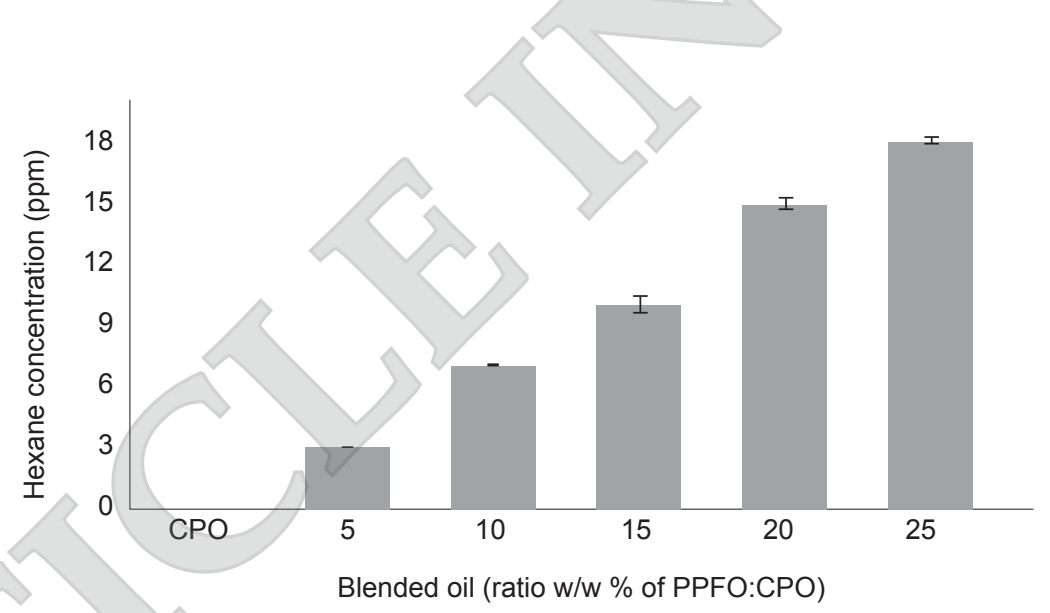

Figure 2. Hexane concentration of crude palm oil (CPO) blended with different dosage of palm pressed-fibre oil (PPFO). Results are mean values ( $n=3$ ) by triplicate blending oil samples. Error bars represent the standard deviations of mean values.

al., 2011; Nur Sulihatimarsyila et al., 2019). High extraction temperature also led to hydrolysis of the residual oil and thus, increased the FFA values (Rusnani et al., 2012; Che Man, et al., 1999; Japir et al., 2017; Bahadi et al., 2016). Table 1 exhibited that PPFO and CPO have various initial FFA values and theroretically correlated with the effects of physical blending on the quality properties. As a result, blending of PPFO with CPO gradually increased FFA values from $3.42 \pm 0.04 \%$ to $3.91 \pm 0.06 \%$ with the increased in PPFO from 0\%-25\% (w/w of CPO) as shown in Figure 3. This result indicates that FFA value would increase by $2 \%$ for every $5 \%(\mathrm{w} / \mathrm{w})$ PPFO dosage into CPO.

\section{Effect on Deterioration of Bleachability Index (DOBI)}

The DOBI indicates the oxidation rate of the product and the ease of refining for the oil. High DOBI value implies that the fruit is fresh, ripe and free of contaminants. Results showed that DOBI values for PPFO were relatively lower than $\mathrm{CPO}$, from 1.62 to 2.02 and 2.43 to 2.83 , respectively (Table 1). The result was in agreement with other studies conducted by Ummi Kalsum and Rohaya (2019) and Nur Sulihatimarsyila et al. (2019). DOBI value is one of the main indicators to show the deterioration of the oil. Good quality oil 


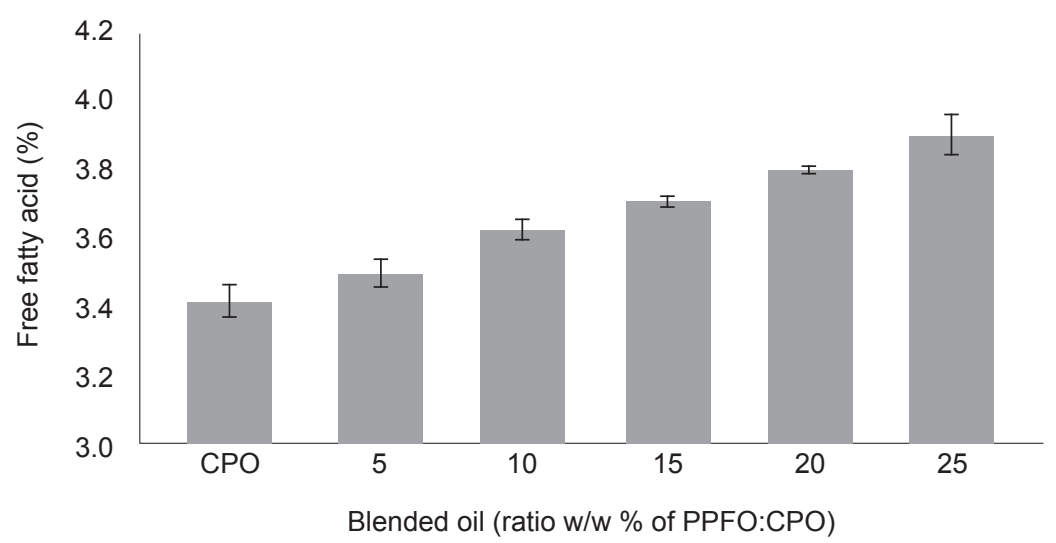

Figure 3. Free fatty acid (FFA) value of crude palm oil (CPO) blended with different dosage of palm pressed-fibre oil (PPFO). Results are mean values $(n=3)$ by triplicate blending oil samples. Error bars represent the standard deviations of mean values.

has a DOBI value of more than 2.3 as specified in MS 814:2007 (Farah Khuwailah et al., 2019). Overheating and oxidation of palm pressed fibre during processing could have contributed to low DOBI value (Rusnani et al., 2012; Tan et al., 2017). Other factors contributing to low DOBI values are prolonged storage before processing and contamination by other materials contained in the pressed fibre. Ummi Kalsum and Rohaya (2019) suggested that the variation in DOBI values among the mills could be attributed to differences in operating parameters and mill practices for solvent extraction. Blending results showed that the DOBI values decreased from $2.76 \pm 0.04$ to 2.33 \pm 0.03 with the increment of PPFO dosage (from $0 \%-25 \% \mathrm{w} / \mathrm{w}$ ) into $\mathrm{CPO}$ as shown in Figure 4. These results showed that the decrease in DOBI values is proportional to the addition of PPFO into CPO. This blending result indicates that blending more than $25 \%(\mathrm{w} / \mathrm{w})$ PPFO into CPO will lower DOBI values to less than 2.3, lower than the specification of PORAM in MS 814:2007 (Farah Khuwailah et al., 2019).

\section{Effect on Phosphorus Content}

The phosphatides content in good quality CPO normally ranged between 10-20 ppm. Elemental analysis of phosphorus (P) indicated the presence of phospholipids in oil. Previous study showed that good quality $\mathrm{CPO}$ containing lower phosphorus content (below than $20 \mathrm{ppm}$ ) would exhibit very low level of trace metals, such as iron and copper. Ai (1990) reported that the ideal amount of phosphorus content for good quality $\mathrm{CPO}$ is $15 \mathrm{ppm}$. High acidity $\mathrm{CPO}$ which showed high phosphorus content, exceeding 30 ppm, would affect the oil stability which imparts undesirable level of impurities and gums trace metals such as iron and copper. Studies also showed that high amount of phospholipids would destroy the vitamin A in CPO (Goh et al., 1984; Lau et al., 2006; Rakmi et al., 1983). It is thus, desirable to have low phospholipids levels in the blended oils for better oxidative stability and easier bleaching process. However, results from this study showed that PPFO contain significant

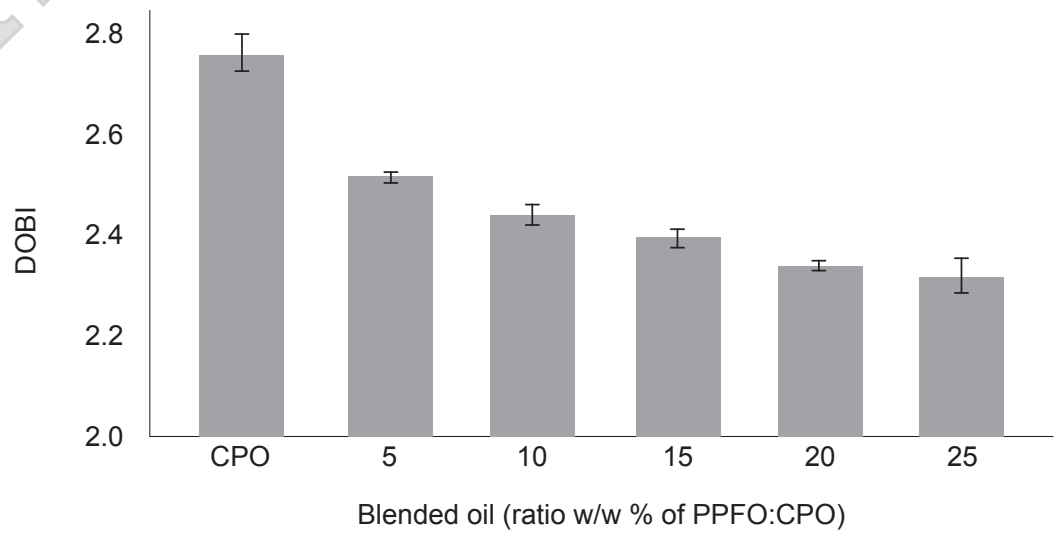

Figure 4. Deterioration of bleachability index (DOBI) of crude palm oil (CPO) blended with different dosage of palm pressed-fibre oil (PPFO). Results are mean values $(n=3)$ by triplicate blending oil samples. Error bars represent the standard deviations of mean values. 
amount of phosphorus (214-247 ppm), while $\mathrm{CPO}$ has lower phosphorus content (16-27 ppm) (Table 1). Ummi Kalsum and Rohaya (2019) also reported phosphorus content of up to $1063 \mathrm{pm}$ in PPFO sample in one of the palm oil mills surveyed by MPOB (Table 1). As reported by Goh et al. (1982), oil from solvent extracted ripe fruits mesocarp fibre contains high amount of phospholipids (1000-2000 ppm) compared to commercial CPO (20-80 ppm). Results from this study showed that phosphorus content in blended oil increased gradually from $34.67 \pm 3.48 \mathrm{ppm}$ to $63.84 \pm 4.02 \mathrm{ppm}$ as the ratio of PPFO increased from $0 \%-25 \%(\mathrm{w} / \mathrm{w}$ of $\mathrm{CPO})$ (Table 2). This shows that high PPFO dosage will increase the phosphorus level in $\mathrm{CPO}$, which in turn, will complicate the $\mathrm{CPO}$ refining process. Consequently, high amount of bleaching earth is required, which subsequently incur high cost for refining processes (Ummi Kalsum and Rohaya, 2019; Lau et al., 2013). In addition, the initial phosphorus content in CPO and PPFO is crucial to ensure blending CPO with PPFO would not affect the downstream processing. This blending result suggested that phosphorus content will increase by $15 \%$ for every $5 \%(\mathrm{w} / \mathrm{w})$ of PPFO blended into CPO.

\section{Effect on Chlorine Content}

Chloride ion was identified as one of the main precursor of 3-MCPD esters formation in refined palm oil (Freudenstein et al., 2013; Ramli et al., 2015). 3-MCPD esters is generally formed when acylglycerols in oil reacted with high temperature $\left(260^{\circ} \mathrm{C}\right)$ in the presence of chloride ion during deodorisation in refining process (Parveez et al., 2019; Ramli et al., 2015). In a random survey led by $\mathrm{MPOB}$, the total chlorine content in CPO from eight palm oil mills in 2018 and 2019 ranged from 1.9510.89 ppm (Ramli et al., 2015; Ummi Kalsum and Rohaya, 2019). Several years later, Ummi Kalsum and Rohaya (2019) reported that PPFO contains
23.41-127.23 ppm of chlorine as depicted in Table 1. Theroretically, physical blending of $\mathrm{CPO}$ with $\mathrm{PPFO}$ would result in increment of chlorine contents in the blended oil. The concentration of chlorine in the blended oils increased, with the increased in PPFO dosage (from $0 \%-25 \% \mathrm{w} / \mathrm{w}$ of CPO) with the results being in the range from 3.85-7.49 ppm. Consequently, this resulted in the increment of $3-M C P D$ esters formation in blended oil and in refined palm oil when heated at higher temperature (Ramli et al., 2015). Study conducted by Ummi and Rohaya (2019) is an evident that blending CPO with PPFO would increase 3-MCPD esters from 0.2$15 \mathrm{ppm}$ when PPFO was added up to $10 \%(\mathrm{w} / \mathrm{w})$ into CPO. In fact, in October 2018, the European commission suggested two maximum levels of 3 -MCPD esters in refined vegetable oil, which are $1.25 \mathrm{ppm}$ for oils and fats (coconut, maize, rapeseed, sunflower, soyabean and palm kernel) and $2.5 \mathrm{ppm}$ for other vegetables oil, fish oil and also mixture of oils and fats (Parveez et al., 2019; Ummi Kalsum and Rohaya, 2019).

\section{Effect on Heavy Metal Content}

Rakmi et al. (1983) reported that heavy metals such as iron and copper are active prooxidants that would accelerate the oxidation process in CPO. Heavy metals would also catalyse the decomposition of hydroproxides to free radicals and hastened the oxidation process. Flider and Orthoefer (1981) reported that similar reaction was observed in other oils such as soyabean oil where its quality deteriorated when iron and copper's concentrations were greater than $30 \mathrm{ppb}$ and $5 \mathrm{ppb}$, respectively. Ames et al. (1960) also reported that high amount of iron content in $\mathrm{CPO}$ would complicate the bleaching process in refinery, while copper would increase the colour of refined palm oil from 2.0 to 4.8 Red Lovibond. Previous studies showed that maximum level of iron and copper in

TABLE 2. TRACE ELEMENTS CONTENT IN CRUDE PALM OIL (CPO), PALM PRESSED-FIBRE OIL (PPFO) AND BLENDED OILS (BO)

\begin{tabular}{|ccccc}
\hline \multirow{2}{*}{ Samples } & \multicolumn{4}{c}{ Trace elements concentration $(\mathbf{p p m})$} \\
\cline { 2 - 5 } & Iron $(\mathrm{Fe})$ & Copper $(\mathbf{C u})$ & Phosphorus $(\mathbf{P})$ & Chloride $(\mathbf{C l})$ \\
\hline & $(\mathbf{p p m})$ & $(\mathbf{p p m})$ & $\mathbf{( p p m )}$ & $\mathbf{( p p m )}$ \\
\hline PPFO & $45.09 \pm 0.03$ & $0.66 \pm 0.02$ & $228.05 \pm 0.04$ & $23.41 \pm 0.03$ \\
CPO & $13.58 \pm 0.02$ & $0.19 \pm 0.03$ & $34.67 \pm 0.01$ & $3.85 \pm 0.02$ \\
BO5\%PPFO & $14.63 \pm 0.02$ & $0.22 \pm 0.01$ & $44.23 \pm 0.03$ & $5.13 \pm 0.04$ \\
BO10\%PPFO & $15.45 \pm 0.03$ & $0.27 \pm 0.02$ & $45.72 \pm 0.02$ & $5.82 \pm 0.03$ \\
BO15\%PPFO & $17.26 \pm 0.04$ & $0.30 \pm 0.03$ & $52.91 \pm 0.02$ & $6.49 \pm 0.02$ \\
BO20\%PPFO & $15.96 \pm 0.03$ & $0.35 \pm 0.02$ & $57.31 \pm 0.03$ & $6.66 \pm 0.03$ \\
BO25\%PPFO & $17.63 \pm 0.02$ & $0.38 \pm 0.01$ & $63.84 \pm 0.02$ & $7.49 \pm 0.02$ \\
\hline
\end{tabular}

Note: Results are mean values $(\mathrm{n}=3$ ) by triplicate blending oil samples. 
refined palm oil to be exported to Australia were 500 ppb and 10 ppb, respectively (Rakmi et al., 1983; Berger, 1982). The concentrations of heavy metals in PPFO, namely iron (45.09 ppm) and copper (0.66 ppm) were higher compared to CPO (Table 2). Blending $\mathrm{CPO}$ with PPFO would result in the increment of heavy metals concentrations in the blended oil. The concentration of iron and copper in the blended oils had increased, with the increase in PPFO dosage (from $0 \%-25 \% \mathrm{w} / \mathrm{w}$ of CPO) in the range from $13.58-17.63 \mathrm{ppm}$ and $0.19-0.38 \mathrm{ppm}$, respectively. This result showed that high initial amount of heavy metals content in PPFO would effect the blended oils and increase by $5 \%$ for every $5 \%(\mathrm{w} / \mathrm{w})$ PPFO dosage blended into CPO.

\section{Effect on Iodine Value (IV)}

IV is another important parameter that indicates the oil oxidative stability and for determining oil identities (Talpur et al., 2010; Ayyildiz et al., 2015). Determination of IV involved measuring the degree of unsaturation or double bonds in fats and oils. Higher IV indicates greater degree of unsaturation, hence, lower oxidative stability (Soek et al., 2019). Table 1 shows that the IV of CPO was higher than PPFO with the values ranges from 51.96-53.22 and 49.11-51.22, respectively. The decrease in IV in PPFO can be attributed to the destruction of double bonds by oxidation or polymerisation. Comparing with $\mathrm{CPO}$, the IV in blended oils decreased from 51.96 \pm 0.37 to $50.21 \pm 0.03$ with the increased in PPFO dosage from $0 \%$ to $25 \% \mathrm{w} / \mathrm{w}$ of CPO (Figure 5). This indicated that there is an increase in saturated fatty acids (SFA) when CPO is blended with PPFO as this oil contained high SFA compositions (Table 4). This result is in agreement with findings by Soek $e t$ al. (2019) which indicated that IV in PPFO is lower than $\mathrm{CPO}$, implying a higher saturation level in $\mathrm{PPFO}$ as compared to CPO.

\section{Effect on Oil Oxidative Stability}

Oxidative stability is a significant parameter in evaluating the shelf life of oils and fats. FAC and minor components such as tocols, FFA and IV could affect the oil oxidative stability (Bozan and Temelli, 2008; Ayyildiz et al., 2015; Cao et al., 2014). Oxidative stability is interrelated with the compositions of fatty acids, in which when more unsaturated fatty acids (UFA) are present in the edible oil, the oxidation reaction will occur faster (Liu and White, 1992; Ramli et al., 2017; Magdalena et al., 2018). CPO contains slightly higher UFA $(51.96 \%)$ compared to PPFO (49.11\%) (Table 4). UFA in palm oil comprises of C18:3 (linolenic acid), C18:2 (linoleic acid) and C18:1 (oleic acid). Previous studies have found that linolenic acid was the first to be oxidised, followed by linoleic acid and oleic acid (Liu and White, 1992; Magdalena et al., 2018). $\mathrm{CPO}$ showed lower oxidative stability with shorter induction time (14-17 hr) in Rancimat test compared to PPFO (18-25 hr) (Table 1). As a result, blending PPFO with CPO stabilised the CPO, whereby the oxidative values of the blended oils varied from $14.31 \pm 1.50 \mathrm{hrs}$ to $16.76 \pm 0.74 \mathrm{hrs}$. The oxidative stability of the blended oils of up to $25 \%(\mathrm{w} / \mathrm{w})$ PPFO was comparable to $\mathrm{CPO}$ as depicted in Figure 6. PPFO contains of high amount of carotenes that consist of antioxidants properties. This would contribute to the increased stability of the blended oils.

\section{Effect on Phytonutrients Content}

Table 3 shows the phytonutrients content in $\mathrm{CPO}, \mathrm{PPFO}$ and blended oils. PPFO that was commercially produced by solvent extraction at the palm oil mill contained higher amount of carotenes (1258-1750 ppm) compared to CPO (537$572 \mathrm{ppm})$ (Table 1). These results are in agreement

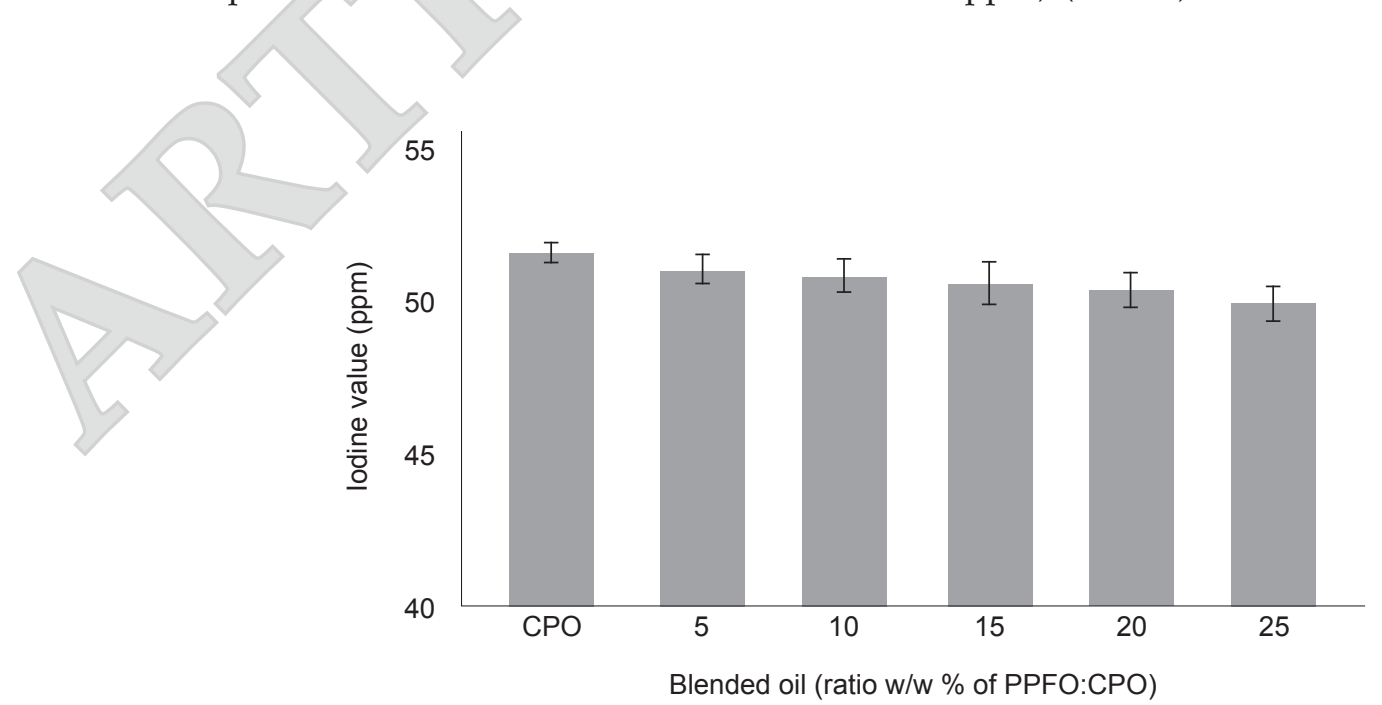

Figure 5. Iodine value (IV) of crude palm oil (CPO) blended with different dosage of palm pressed-fibre oil (PPFO). Results are mean values ( $n=3$ ) by triplicate blending oil samples. Error bars represent the standard deviations of mean values. 
TABLE 3. PHYTONUTRIENTS CONTENT IN CRUDE PALM OIL (CPO) PALM PRESSED-FIBRE OIL (PPFO) AND BLENDED OILS (BO)

\begin{tabular}{|c|c|c|c|c|c|c|c|}
\hline \multirow{2}{*}{ Phytonutrients } & \multirow{2}{*}{ СРO } & \multirow{2}{*}{ PPFO } & \multicolumn{5}{|c|}{ Blended oil (\% w/w PPFO: CPO) } \\
\hline & & & BO5\% $\%$ PPFO & ВО10\% PPFO & BO15\% PPFO & ВО20\% PPFO & BO25\% PPFO \\
\hline Carotene (ppm) & $539 \pm 14$ & $1481 \pm 27$ & $554 \pm 5$ & $608 \pm 68$ & $609 \pm 22$ & $623 \pm 14$ & $654 \pm 8$ \\
\hline Sterol (ppm) & $433 \pm 8$ & $1529 \pm 1$ & $444 \pm 25$ & $497 \pm 15$ & $540 \pm 33$ & $629 \pm 21$ & $808 \pm 17$ \\
\hline Squalene (ppm) & $475 \pm 7$ & $1721 \pm 10$ & $780 \pm 8$ & $881 \pm 5$ & $962 \pm 4$ & $1048 \pm 7$ & $1201 \pm 9$ \\
\hline Vitamin E (ppm) & $1185 \pm 64$ & $1609 \pm 71$ & $1489 \pm 9$ & $1494 \pm 10$ & $1591 \pm 22$ & $1607 \pm 89$ & $1626 \pm 92$ \\
\hline \multicolumn{8}{|c|}{ Composition of tocopherol and tocotrienol (\%) } \\
\hline - $\alpha$-tocopherol & 5 & 24 & 5 & 5 & 6 & 6 & \\
\hline - $\alpha, \beta, \gamma, \delta$-tocotrienols & 95 & 76 & 95 & 95 & 94 & 94 & \\
\hline
\end{tabular}

Note: Results are mean values $(\mathrm{n}=3)$ by triplicate blending oil samples.

TABLE 4. COMPARISON OF FATTY ACID COMPOSITIONS AND ACYLGLYCERIDES OF CRUDE PALM OIL (CPO), PALM PRESSED-FIBRE OIL (PPFO) AND BLENDED OILS

\begin{tabular}{|c|c|c|c|c|c|c|c|c|}
\hline & \multirow{2}{*}{ СРO } & \multirow{2}{*}{ PPFO } & \multicolumn{5}{|c|}{ Blended oil (\% w/w PPFO: CPO) } & \multirow{2}{*}{$\begin{array}{c}\text { MS } \\
814: 2007\end{array}$} \\
\hline & & & ВО5\% $\%$ PFO & ВО10 $\%$ РPFО & ВО15\% $\%$ РFО & BO20\% $\%$ PFO & BO25\% PPFO & \\
\hline \multicolumn{9}{|c|}{ Fatty acid compositions (\%) } \\
\hline \multicolumn{9}{|c|}{ Saturated fatty acids (SFA) } \\
\hline C12:0 & $0.19 \pm 0.02$ & $1.33 \pm 0.05$ & $0.24 \pm 0.01$ & $0.28 \pm 0.01$ & $0.34 \pm 0.01$ & $0.39 \pm 0.02$ & $0.42 \pm 0.03$ & $0.1-0.4$ \\
\hline C14:0 & $1.00 \pm 0.02$ & $1.34 \pm 0.01$ & $1.00 \pm 0.02$ & $1.02 \pm 0.00$ & $1.03 \pm 0.02$ & $1.05 \pm 0.01$ & $1.07 \pm 0.01$ & $1.0-1.4$ \\
\hline $\mathrm{C} 16: 0$ & $45.69 \pm 0.09$ & $41.22 \pm 0.02$ & $45.56 \pm 0.21$ & $45.16 \pm 0.14$ & $44.82 \pm 0.04$ & $44.63 \pm 0.05$ & $44.44 \pm 0.02$ & $40.9-47.5$ \\
\hline C18:0 & $3.97 \pm 0.08$ & $4.09 \pm 0.06$ & $4.18 \pm 0.17$ & $4.10 \pm 0.03$ & $4.07 \pm 0.03$ & $4.09 \pm 0.03$ & $4.13 \pm 0.04$ & $3.8-4.8$ \\
\hline \multicolumn{9}{|c|}{ Unsaturated fatty acids (UFA) } \\
\hline $\mathrm{C} 18: 1$ & $41.96 \pm 0.01$ & $39.24 \pm 0.08$ & $39.30 \pm 0.2$ & $39.55 \pm 0.08$ & $39.57 \pm 0.09$ & $39.69 \pm 0.08$ & $39.77 \pm 0.01$ & $36.4-41.2$ \\
\hline C18:2 & $10.00 \pm 0.08$ & $9.87 \pm 0.02$ & $9.70 \pm 0$ & $9.87 \pm 0.07$ & $9.92 \pm 0.04$ & $9.89 \pm 0.03$ & $9.90 \pm 0.02$ & $9.2-11.6$ \\
\hline \multicolumn{9}{|c|}{ Acylglycerides (\%) } \\
\hline MAG/FFA & $5.06 \pm 0.01$ & $11.44 \pm 0.01$ & $5.38 \pm 0.01$ & $5.61 \pm 0.03$ & $5.84 \pm 0.02$ & $6.05 \pm 0.05$ & $6.28 \pm 0.00$ & $\mathrm{~N} / \mathrm{A}$ \\
\hline DAG & $5.58 \pm 0.03$ & $9.51 \pm 0.06$ & $5.74 \pm 0.08$ & $5.88 \pm 0.02$ & $6.03 \pm 0.02$ & $6.30 \pm 0.02$ & $6.32 \pm 0.03$ & $\mathrm{~N} / \mathrm{A}$ \\
\hline TAG & $89.36 \pm 0.07$ & $79.05 \pm 0.04$ & $88.89 \pm 0.03$ & $88.52 \pm 0.02$ & $88.13 \pm 0.02$ & $87.74 \pm 0.06$ & $87.44 \pm 0.02$ & $\mathrm{~N} / \mathrm{A}$ \\
\hline
\end{tabular}

Note: MAG - monoacylglycerols; DAG - diacylglycerols; TAG - triaclyglycerols; FFA - free fatty acid; BO - blended oil ; N / A - not available. Results are mean values $(n=3)$ by triplicate blending oil samples.

with findings by Ummi Kalsum and Rohaya (2019), who reported carotenes content in PPFO can be up to $1913 \mathrm{ppm}$. The carotenes content in blended oils increased from $539 \pm 14 \mathrm{ppm}$ to $654 \pm 8 \mathrm{ppm}$ with the increment in PPFO dosage (from 0\%$25 \% \mathrm{w} / \mathrm{w}$ of CPO). Vitamin E (tocopherols and tocotrienols) in palm oil comprises of four major isomers: $\alpha$-tocopherol, $\alpha$-tocotrienol, $\gamma$-tocotrienol and $\delta$-tocotrienol. Vitamin $\mathrm{E}$ is well-known for its antioxidant and nutritional values (Lau et al., 2007; Lau et al., 2008; Neoh et al., 2011; Ng and Choo, 2011; Rusnani et al., 2012; Nur Sulihatimarsyila et al., 2019). Table 3 shows that PPFO has higher amount of vitamin E (1609 $\pm 71 \mathrm{ppm})$ compared to CPO (1185 $\pm 64 \mathrm{ppm})$. The $\alpha$-tocopherol content in PPFO was higher (24\% of total tocols) than CPO (5\% of total tocols) (Table 3). These results are consistent with data obtained from previous findings (Goh et al., 1985; Choo et al., 1996; Ng and Choo, 2011; Rusnani et al., 2012). Results also showed that the composition of tocotrienols in PPFO, which comprised of $\alpha$-tocotrienol, $\gamma$-tocotrienol and $\delta$-tocotrienol, was lower $(76 \%$ of total tocols than CPO $(95 \%$ of total tocols). However, blending $\mathrm{CPO}$ with PPFO affected the tocotrienols and tocopherol compositions in blended oils (Table 5). Compositions of tocopherol in blended oils increased from 5\%-7\% of total tocols while tocotrienols composition decreased from 95\%-93\% of total tocols with the increment in PPFO dosage from $0 \%-25 \%(\mathrm{w} / \mathrm{w})$, respectively. PPFO is also rich in sterols and squalene (Table 3). The concentration of sterols in PPFO (1529 \pm 1 ppm) was higher than $\mathrm{CPO}(433 \pm 8 \mathrm{ppm})$. Squalene content in PPFO $(1721 \pm 10 \mathrm{ppm})$ was higher than $\mathrm{CPO}$ 


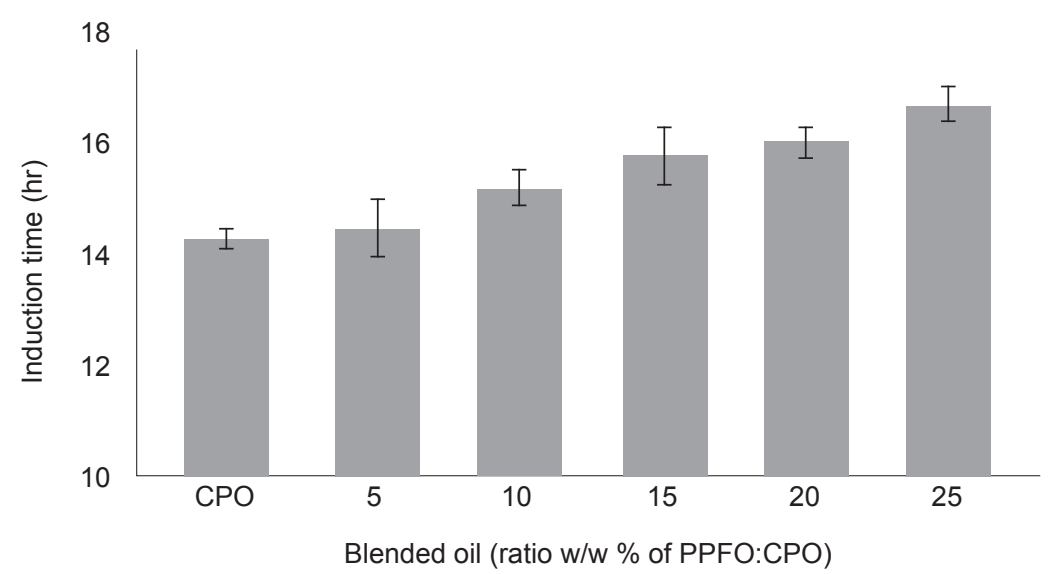

Figure 6. Oxidative stability of crude palm oil (CPO) blended with different dosage of palm pressed-fibre oil (PPFO). Results are mean values ( $n=3)$ by triplicate blending oil samples. Error bars represent the standard deviations of mean values.

(475 $\pm 7 \mathrm{ppm}$ ). Blending of CPO with PPFO from $0 \%-25 \%(\mathrm{w} / \mathrm{w})$ dosage increased the concentrations of sterols and squalene in the blended oils, from $433 \pm 8 \mathrm{ppm}$ to $808 \pm 17 \mathrm{ppm}$ and $475 \pm 7 \mathrm{ppm}$ to $1201 \pm 9$ ppm, respectively.

\section{Effect on Fatty Acid Compositions (FAC) and Acylglycerides}

PPMF from the palm oil mill consists of a mixture of palm mesocarp fibre, shell, crushed kernel and debris. Hence, the oil recovered from this mixture has the characteristics of all these products (Lau et al., 2006; Rusnani et al., 2012). The nutritional status of palm oil is determined by the types of fatty acids contained in palm oil, which consists approximately 50\% SFA with 45\% palmitic acid (C16:0), 5\% stearic acid (C18:0), and trace amount of myristic acid (C14:0) and lauric acid (C12:0) (Sambanthamurthi et al., 2000). The UFA consist of approximately $40 \%$ oleic acid (C18:1), and $10 \%$ polyunsaturated linoleic acid (C18:2) and linolenic acid (C18:3) (Sambanthamurthi et al., 2000; Noh et al., 2002). Table 4 shows the comparison of FAC in PPFO and $\mathrm{CPO}$. The FAC of PPFO is quite similar to $\mathrm{CPO}$ with palmitic $(41.22 \pm 0.02 \%)$ and oleicacids $(39.24 \pm 0.08 \%)$ being the major fatty acids. However, composition of lauric acid in PPFO was significantly higher than CPO $(1.33 \pm 0.05 \%)$. Presence of lauric acid in PPFO had attributed towards contamination of kernel oil as the pressed fibre comprised of mixture of broken nuts and kernels, discharged together with mesocarp fibre after mechanical pressing (Neoh et al., 2011; Rusnani et al., 2012). According to Siew and Berger (1981), lauric acid is present in palm kernel oil with a composition of $48 \%$, which discriminates palm kernel oil from CPO. FAC of the blended oils samples were comparable to those of CPO and remained in the range specified by PORAM in MS 814:2007 (Table 4). However, composition of palmitic acid decreased slightly from $45.69 \pm 0.09 \%$ to $44.44 \pm 0.02 \%$ with the $0 \%$ $25 \%(\mathrm{w} / \mathrm{w})$ PPFO dosage in CPO. Nevertheless, the compositions of lauric, myristic and oleic acids in blended oils increased gradually with the increase in PPFO dosages in CPO, at $0.19 \pm 0.02 \%$ to 0.42 $\pm 0.03 \%, 1.00 \pm 0.02 \%$ to $1.07 \pm 0.01 \%$ and $39.24 \pm$ $0.08 \%$ to $39.77 \pm 0.01 \%$, respectively. CPO constitutes mainly 90\%-98\% TAG, 2-6\% DAG, 2\%-5\% MAG/ FFA and minor composition of phytonutrients (Neoh et al., 2011). Results indicated that PPFO has higher DAG, $9.51 \pm 0.06 \%$, compared to CPO (5.58 $\pm 0.03 \%)$. On the other hand, the TAG content in PPFO (79.05 $\pm 0.04 \%)$ was lower than CPO (89.36 \pm $0.07 \%$ ) (Table 4). It was found that the compositions of DAG in blended oils with PPFO dosage from $0 \%$ $25 \%$ increased slightly, ranging from $5.58 \pm 0.03 \%$ to $6.32 \pm 0.03 \%$, whilst TAG decreased from $89.36 \pm$ $0.07 \%$ to $87.44 \pm 0.02 \%$.

\section{CONCLUSION}

This study has shown that blending CPO with PPFO would deteriorate the original CPO quality, by lowering DOBI and IV and increase levels of phosphorus, FFA, hexane and trace metals, even at low dosage of PPFO. Results indicated that PPFO produced from the commercial solvent extraction plant shows various initial properties. Blending results depicted that physical blending properties would be dependent on initial properties of PPFO and CPO. Furthermore, this blending analysis shows an increment in chloride content, which is one of the main precursors of 3-MCPD esters formation. Thus, it is not recommended to blend PPFO into $\mathrm{CPO}$, as the blended oil deteriorate $\mathrm{CPO}$ quality. Nevertheless, PPFO has better quality than $\mathrm{CPO}$ in terms of phytonutrient contents, signifying its potential in other applications. Instead of blending PPFO with $\mathrm{CPO}$, it is suggested for PPFO to be classified as valuable oil and sold as pharma- 
industrial grade oil since it is rich in phytonutrient and it is suitable for other applications such as pharmaceutical industry and biodiesel.

\section{ACKNOWLEDGEMENT}

The authors would like to thank the DirectorGeneral specifically and management of MPOB generally for the support in conducting this research.

\section{REFERENCES}

Ai, T Y (1990). Analytical techniques in palm and palm kernel oil specifications. $10^{\text {th }}$ Palm Oil Familiarisation Programme (POFP). Bangi.

Ames, G R; Raymond, W D and Ward, J B (1960). The bleachability of Nigerian palm oil. J. Sc. Fd. Agric., 2: 194-202.

AOCS (1997). Quantitative separation of monoglycerides, diglycerides, and triglycerides by silica gel column chromatography. Official Methods and Recommended Practices of the AOCS. AOCS Press, Champaign, Recommended Practice Cd 11c-93.

ASTM (2004). Standard Test Methods for Determination of Organic Chloride Content in Crude Oil (ASTM D4929-04). ASTM International. West Conshohocken, PA, USA.

Awalludin, M F; Sulaiman, O; Hashim, R and Nadhari, W N A W (2015). An overview of the oil palm industry in Malaysia and its waste utilization through thermochemical conversion, specifically via liquefaction. Renewable and Sustainable Energy Reviews, 50: 1469-1484. DOI: 10.1016/j. rser.2015.05.085.

Ayyildiz, H F; Topfaka, M; Kara, H and Sherazi, S T H (2015). Evaluation of fatty acid composition, tocols profile and oxidative stability of some fully refined edible oils. Int. J. Food Properties, 18(9): 20642076.

Azmil Haizam, A T; Raznim Arni, A R; Abdul Niefaizal, A H and Ainie, K (2019). Effect of anticlouding agent on the fate of 3-Monochloropropane1,2-diol esters and glycidyl esters in palm olein during repeated frying. Molecules, 24: 23-32. DOI:10.3390/ molecules24122332.

Bahadi, M A; Japir, A W; Nadia, S and Jumat, S (2016). Free fatty acids separation from Malaysian high free fatty acid crude palm oil using molecular distillation. Malaysian J. Analytical Sciences, 20(5): 1042-1051.
Berger, K G (1982). Refined palm oil quality as received. PORIM Bulletin No. 4: 57-67.

Bozan, B and Temelli, F (2008). Chemical composition and oxidative stability of flax, safflower and poppy seed. Bioresource Technology, 99: 6354-6359.

Cao, J; Lia, H; Xia, X; Zou, X G; Li, J; Zhu, X M and Deng, Z Y (2014). Effect of fatty acid and tocopherol on oxidative stability of vegetable oils with limited air. Int. J. Food Properties, 18: 808-820. DOI:10.1080/1 0942912.2013.864674.

Che Man, Y B; Moh, M H and Van De Voort, F R (1999). Determination of free fatty acids in crude palm oil and refined-bleached-deodorized palm olein using Fourier transform infrared spectroscopy. J. Amer. Oil Chem. Soc., 76(4): 485-490. DOI: 10.1007 / s11746-999-0029-z.

Choo, Y M; Yap, S C; Ooi, C K; Ma, A N; Goh, S H and Ong, A S H (1996). Recovered oil from palmpressed fibre: A good source of natural carotenoids, vitamin E and sterols. J. Amer. Oil Chem. Soc., 73: 599602. DOI:10.1007/BF02518114.

Clough, S R (2014). Hexane. Encyclopedia of Toxicology, 2: 900-904. DOI: 10.1016/b978-0-12-386454-3.00397-3.

Farah Khuwailah, A B; Yeoh, C B and Najwa, S (2019). Revision of Malaysian Standard for Palm Oil- Specification MS 814:2017 (Second revision) Amendment 1:2018 - What's new? Palm Oil Developments, 71: 18-32.

Farhoosh, R (2007). The effect of operational parameters of the Rancimat method on the determination of the oxidative stability measures and shelf-life prediction of soybean oil. J. Amer. Oil Chem. Soc., 84: 205-209. DOI:10.1007/s11746-0061030-4.

Flider, F J and Orthoefer, F T (1981). Metals in soybean oil. J. Amer. Oil Chem. Soc., 58(3): 270-272.

Freudenstein, A; Weking, J and Matthäus, B (2013). Influence of precursors on the formation of 3-MCPD and glycidyl esters in a model oil under simulated deodorization. European J. Lipid Science and Technology, 115(3): 286-294.

Goh, S H; Khor, H T and Gee, P T (1982). Phospholipids of palm oil (Elaeis guineensis). J. Amer. Oil Chem. Soc., 59: 296-299.

Goh, S H; Tong, S L and Gee, P T (1984). Inorganic phosphate in crude palm oil: Quantitative analysis and correlations with oil quality parameters. J. Amer. Oil Chem. Soc., 61: 1601-1604. 
Goh, S H; Choo, Y M and Ong, S H (1985). Minor constituents of palm oil. J. Amer. Oil Chem. Soc., 62: 237-240. DOI: 10.1007 / BF02541384.

Japir, A A W; Salimon, J; Derawi, D; Bahadi, M; AlShuja'a, S and Yusop, M R (2017). Physicochemical characteristics of high free fatty acid crude palm oil. Oilseeds and Fats, Crops and Lipids, 24(5). DOI:10.1051/ ocl/ 2017033.

Jeong, E J; Lee, S H; Kim, B T; Lee, G; Yun, S S; Lim, H S and Kim, Y S (2017). An analysis method for determining residual hexane in health functional food products using static headspace gas chromatography. Food Sci. Biotechnol., 26(2): 363368. DOI 10.1007/s10068-017-0049-7.

Kumar, N and Gow, J G (1994). Residual solvent analysis by headspace gas chromatography. J. Chromatography, A: 667: 235-440.

Kumar, S P J; Prasad, S R; Banerjee, R; Agarwal, D K; Kulkarni, K S and Ramesh, K V (2017). Green solvents and technologies for oil extraction from oil seeds. Chemistry Central J., 11(1): 1-7. DOI:10.1186/ s13065-017-0238-8.

Lau, H L N; Choo, Y M; Ma, A N and Chuah, C H (2006). Quality of residual oil from palmpressed mesocarp fibre (Elaeis guineensis) using supercritical $\mathrm{CO}_{2}$ with and without ethanol. J. Amer. Oil Chem. Soc., 83(10): 893-898. DOI:10.1007/ s11746-006-5043-9.

Lau, H L N; Choo, Y M; Ma, A N and Chuah, C $\mathrm{H}$ (2007). Extraction and identification of watersoluble compounds in palm-pressed fibre by SC$\mathrm{CO}_{2}$ and GC-MS. J. Amer. Environ. Sci. 3: 54-59.

Lau, H L N; Choo, Y M; Ma, A N and Chuah, C $\mathrm{H}$ (2008). Selective extraction of palm carotene and vitamin $E$ from fresh palm-pressed mesocarp fibre (Elaeis guineensis) using supercritical $\mathrm{CO}_{2} . \mathrm{J}$. Food Engineering, 84(2): 289-296. DOI: 10.1016/j. jfoodeng.2007.05.018.

Lau, H L N; Nur Sulihatimarsyila, A W and Choo, Y M (2013). Novel refining technology of palm pressed fibre oil. MPOB Information Series No. 536.

Lau, H L N; Nur Sulihatimarsyila, A W; Nabilah, K M (2017). Recovery and refining of palm-pressed mesocarp fiber oil. Proc. MPOB Int. Palm Oil Congress 2017. p. 206-216.

Liu, H R and White, P J (1992). Oxidative stability of soybean oils with altered fatty acid. J. Amer. Oil Chem. Soc., 69: 528-532.
Magdalena, M; Florowska, A; Dluzewska, E; Wroniak, M; Katarzyna, M L and Zbikowska, A (2018). Oxidative stability of selected edible oils. Molecules, 23: 1746.

Neoh, B K; Thang, Y M; Zain, M Z M and Junaidi, A (2011). Palm pressed fibre oil: A new opportunity for premium hardstock? International Food Research J., 18: 769-773.

Ng, M H and Choo, Y M (2011). Phytonutrients in palm: Occurrence and properties. Palm Oil: Nutrition, Uses and Impacts (Palmetti, M L ed.). Nova Science Publishers. p. 47-71.

Noh, A; Rajanaidu, N; Kushairi, A; Rafii, M R; Mohd Din, A and Saleh G (2002). Variability in fatty acid composition, iodine value and carotene content in the MPOB oil palm germplasm collection from Angola. J. Oil Palm Res., 14: 18-23.

Noorshamsiana, A W; Astimar, A A; Iberahim, N I; Nor Faizah, J; Anis, M; Hamid, F A and Kamarudin, $\mathrm{H}$ (2017). The quality of oil extracted from palm pressed fibre using aqueous enzymatic treatment. J. Oil Palm Res., 29(4): 588-593. DOI:10.21894/ jopr.2017.0004.

Nor Faizah, J; Noorshamsiana, A W; Wan Hasamudin, W H; Kamarudin, H; Nahrul Hayawin, $\mathrm{Z}$ and Mohamad Faizal, I (2020). Extraction and purification of phytosterols mixture from palm fatty acid distillate (PFAD) using multistage extraction processes. J. Oil Palm Res., 33(1): 93-102.

Nur Sulihatimarsyila, A W; Lau, H L N; Nabilah, K M and Nur Azreena, I (2019). Refining process for production of refined palm-pressed fibre oil. Industrial Crops and Products, 129: 488-494. DOI: 10.1016/j.indcrop.2018.12.034.

Oh, C H; Kwon, Y K; Jang, Y M; Lee, D L and Park, $\mathrm{J}$ (2005). Headspace analysis for residual hexane in vegetable oil. Food Sci. Biotechnol., 14(4): 456- 460.

Onoja, E; Chandren, S; Abdul Razak, F I; Mahat, N A and Wahab, R A (2019). Oil palm (Elaeis guineensis) biomass in Malaysia: The present and future prospects. Waste and Biomass Valorization, 10: 2099-2117. DOI:0.1007/s12649-018-0258-1.

Othman, A; Goggin, K A; Tahir, N I; Brodrick, E; Singh, R; Sambanthamurthi, R; Parveez, G K A; Davies, A N; Murad, A J; Muhammad, N H; Ramli, U S and Murphy, D J (2019). Use of headspace-gas chromatography-ion mobility spectrometry to detect volatile fingerprints of palm fibre oil and sludge palm oil in samples of crude palm oil. BMC Research Notes, 12: 229. DOI:10.1186/s13104-019-4263-7. 
Parveez, G K A; Azmil Haizam, A T; Hasliyanti, A and Ahmad Kushairi, D (2019). Palm oil sterilisation technologies and their implications on oil loss, quality and food safety. International Planters Conference. 15-17 July 2019. p. 97-108.

Parveez, G K A; Hishamudin, E; Loh, S K; Meilina, O A; Salleh, K M; Bidin, M N I Z; Sundram, S; Hasan, Z A A H and Idris, Z (2020). Oil palm economic performance in Malaysia and R\&D progress in 2019. J. Oil Palm Res., 32(2): 159-190.

Phoon, K Y; Ng, H S; Rabitah, Z; Yim, H S and Mokhtar, M N (2018). Enrichment of minor components from crude palm oil and palm-pressed mesocarp fibre oil via sequential adsorptiondesorption strategy. J. Ind. Crops Prod. 113: 187-195.

Rakmi, A R; Kalm, M and Wan Nor, W M (1983). Reduction of palm oil heavy metal content in the refining process. PORIM Bulletin, 9: 16-21.

Ramli, NAS; Mohd Noor, MA; Musa, H and Ghazali, R (2017). Stability evaluation of quality parameters for palm oil products at low temperature storage. J. Sci. Food Agric., 98(9): 3351-3362.

Ramli, M R; Siew, W L; Ibrahim, N A; Kuntom, A and Abd. Razak, R A (2015). Other factors to consider in the formation of chloropropandiol fatty esters in oil processes. Food Additives and Contaminants: Part A: Chemistry, Analysis, Control, Exposure and Risk Assessment, 32(6): 817-824.

Rusnani, A M; Mohammad, A W and Choo, Y M (2012). Properties of residual palm pressed fibre oil. J. Oil Palm Res., 24: 1310-1317.

Saad, B; Ling, C W; Jab, M S; Lim, B P; Mohamad Ali, A S; Wai, W T and Saleh, M I (2007). Determination of free fatty acids in palm oil samples using non-aqueous flow injection titrimetric method. Food Chem, 102(4): 1407-1414. DOI: 10.1016/j. foodchem.2006.05.051.

Sambanthamurthi, R; Sundram, K and Tan, Y (2000). Chemistry and biochemistry of palm oil. Progress in Lipid Research, 39: 507-558.

Sarmidi, M R; Enshasy, H A E and Hamid, M A (2009). Oil palm: The rich mine for pharma, food, feed and fuel industries. American-Eurasian J. Agric. and Environ. Sci., 5(6): 767-776.
Serrato, A G (1981). Extraction of oil from soybeans. J. Amer. Oil Chem. Soc., 58: 157-159.

Siew, W L and Berger, K G (1981). Malaysian palm kernel oil chemical and physical characteristics. PORIM Technology No. 6. PORIM, Bangi.

Soek, S T; Harrison, L N L and Siau, H M (2019). Palm-pressed mesocarp fibre oil as an alternative carrier oil in emulsion. J. Oleo Science, 68(8): 803-808.

Talpur, M Y; Sherazi, S T H; Mahesar, S A and Bhutto A A (2010). A simplified UV spectrometric method for determination of peroxide value in thermally oxidized canola oil. Talanta, 80: 1823-1826.

Tan, C H; Ariffin, A A; Ghazali, H M; Tan, C P; Kuntom, A and Choo, A C (2017). Changes in oxidation indices and minor components of low free fatty acid and freshly extracted crude palm oils under two different storage conditions. J. Food Science and Technology, 54(7): 1757-1764. DOI:10.1007/s13197017-2569-9.

Ummi Kalsum, H M N and Rohaya, M H (2019). Pressed fibre oil: Quality and implication. Palm Oil Engineering Bulletin, 131: 16-21.

Valeria, D P; Felipe, CL; Raquel, G V; Rafael, M; Roger, W; Ayres, P L; Denis, M G F; Maria, A; Apostolis, K; Marcio, A A M and Marcelo, B R (2017). Ultrasoundassisted extraction of bioactive compounds from palm pressed fibre with high antioxidant and photoprotective activities. J. Ultrason. Sonochem., 36: 362-366.

Vijaya, S; Ravi Menon, N; Helmi, S and Choo, Y M (2013). The development of a residual oil recovery system to increase the revenue of a palm oil mill. J. Oil Palm Res., 25: 116-122.

Workman, D (2020). Palm oil imports by country. http: / / www.worldstopexports.com / palm-oilimports-by-country/, accessed on 21 July 2020.

Yusoff, S (2006). Renewable energy from palm oil-Innovation on effective utilization of waste. J. Cleaner Production, 14(1): 87-93. DOI: 10.1016/j. jclepro.2004.07.005.

Yousefi, M and Hosseini, H (2017). Evaluation of hexane content in edible vegetable oils consumed in Iran. J. Experimental and Clinical Toxicology, 1: 27-30. DOI: 10.14302 / issn.2641-7669.ject-17-1790. 